\title{
Juan Bautista Alberdi: o Pensamento Político e Econômico de um Liberal Latino-Americano no Século XIX
}

\author{
Márcio Bobik Braga
}

\begin{abstract}
Resumo: Este artigo tem como objetivo entender o pensamento político e econômico de um intelectual argentino do século XIX: Juan Bautista Alberdi. Tal interpretação baseia-se em duas das principais obras do autor: Bases y Puntos de Partida para la Organización Política de la República Argentina, escrito originalmente em 1852, e a obra póstuma Estudios Económicos, publicada originalmente em 1886. Juan Bautista Alberdi foi um pensador preocupado com a construção institucional da Argentina em uma das fases mais importantes da história do capitalismo mundial. Procurou entender o seu país a partir de uma perspectiva liberal, porém sem simplesmente importar e aceitar as teorias desenvolvidas na Europa ou nos Estados Unidos. Tentaremos responder à seguinte questão: o que pensava um liberal latino-americano no século XIX em um país cujas instituições e as relações políticas ainda estão para serem construídas? A partir da leitura das obras de Alberdi, poderemos perceber várias questões fundamentais para a compreensão do processo de formação econômica e política da América Latina.
\end{abstract}

Palavras-chave: História do Pensamento Econômico Latino-americano, América Latina, História da América Latina, Argentina, liberalismo.

\begin{abstract}
This article aims to contribute to the interpretation of the political and economic thought of the Argentine intellectual of the nineteenth century: Juan Bautista Alberdi. Such interpretation is based on two of the author's main works: Bases y Puntos de Partida para la Organización Política de la República Argentina, written originally in 1852, and Estudios Económicos, originally published in 1886. Juan Bautista Alberdi was a philosopher concerned about Argentinean institutional construction, in one of the most important moments of expansion of world capitalism. He managed to understand his country from a liberal perspective, not simply by importing and accepting theories developed in Europe or in the United States. This paper aims to answer the following question: what did a liberal Latin American one in the nineteenth century think, in a country where institutions and political relations still have to be constructed? From the reading of the texts produced by Alberdi, we can find several important issues for the understanding of the economic and political formation process of Latin America.
\end{abstract}

Keywords: Latin American economic thought, Latin American, Latin America History, Argentina, liberalism.

$(*)$ Professor do Departamento de Economia da USP, campus de Ribeirão Preto e do PROLAM/USP. E-mail: $<$ marbobik@usp.br>. Recebido em 1․7.2010 e aceito em 8.6.2011. 


\section{INTRODUÇÃO}

Como teria sido o pensamento político e econômico predominante na América Latina no século XIX? E qual seria o liberalismo defendido? Não existe uma única resposta para essas perguntas. Mas podemos considerar as posições de um autor que produziu inúmeras obras de interpretação da realidade latino-americana: Juan Bautista Alberdi, um destacado intelectual argentino que viveu entre 1810 e 1884 . Buscaremos compreender o seu pensamento a partir da leitura de dois dos seus principais textos: Bases y Puntos de Partida para la Organización Política de la República Argentina, publicado originalmente em 1852 e a obra póstuma Estudios Económicos, escrito provavelmente no final da década de 1870 e publicado pela primeira vez em 1886.

A escolha baseou-se no conteúdo político e econômico e na importância do momento histórico em que foram concebidas. A escolha da Região do Prata, particularmente a Argentina, coloca-se como relevante por uma característica: tratava-se de um território com a ausência de instituições e onde o poder político e a estrutura econômica estavam para serem criados. Ou seja, na região ainda não havia uma Nação. Tudo estava para ser construído e diferentes opções podiam ser consideradas. Neste sentido, as percepções do autor podem contribuir para a construção de imagens sobre trajetórias alternativas em relação aos caminhos percorridos pela Região do Prata e, sob uma perspectiva mais ampla, pela América Latina.

São várias as justificativas para considerar Alberdi na história do pensamento latino-americano. Foi um autor que contribuiu para a formação de um grupo de intelectuais que procurou "inventar" a Argentina ${ }^{(1)}$. Desde sua morte, seus escritos têm sido considerados nos estudos sobre a formação histórica, econômica e política das ex-colônias espanholas ${ }^{(2)}$. Também é considerado por muitos como sendo o primeiro filósofo latino-americano ${ }^{(3)}$.

Alberdi viveu em uma época em que as ex-colônias espanholas buscavam estabelecer algum projeto político e econômico que significasse o progresso material ou pelo menos alguma estabilidade política em meio ao vazio deixado pelo fim da dominação e exploração colonial. No novo contexto, além das disputas territoriais, surgiram vários conflitos em torno de questões como a divisão do poder político e econômico, particularmente em relação à distribuição das receitas tributárias. Alberdi percebeu, nesses conflitos, ações que estariam comprometendo o processo de formação das instituições necessárias para a criação de uma nação estável e viável. Em seus primeiros escritos, havia grande otimismo em relação ao progresso econômico e político na região. Esse otimismo pode ser percebido no texto Bases. Porém, os rumos tomados pela Argentina durante a segunda metade do século XIX deixaram Alberdi perplexo e pessimista.

(1) Essa geração ficou conhecida como Geração de 37 e foi constituída por alguns grandes escritores e intelectuais, que fizeram oposição política ao modelo socioeconômico produzido pelo ao Governo de Rosas. Fizeram parte dessa Geração personalidades como Domingo Faustino Sarmiento e Esteban Echevérria. Uma interessante interpretação sobre a formação da Geração de 37 pode ser encontra em SHUMWAY (2008).

(2) Sobre essa importância, ver DONGHI (2007). Outro importante tex to sobre a relevância das ideias de Alberdi pode ser encontrado em TERAN (2004). A partir desse autor, pode-se também ler uma densa análise sobre a evolução do pensamento de Alberdi em vários de seus aspectos.

(3) Essa posição decorre do texto Ideas para presidir a la confección del curso de filosofía contemporánea, publicada originalmente em 1842. Sobre o Alberdi filósofo, ver GHIRARDI (2000) ou GULDBERG (2003). 
O autor foi um dos primeiros a perceber que o capitalismo e o "processo civilizatório" que começava a se estabelecer naquelas terras excluíam os gauchos, os caudilhos e uma possível estrutura econômica alternativa àquela que estava sendo implantada, ou seja, o processo estaria absorvendo a sociedade do interior sem necessariamente considerar seus interesses. Discutiu as implicações econômicas e sociais da recusa de Buenos Aires em compartilhar suas receitas aduaneiras com as demais províncias da Região. Denunciou a barbárie das guerras, inclusive a Guerra do Paraguai, como sendo fonte de desperdícios de recursos humanos, materiais e financeiros, causas da instabilidade institucional e adequadas a determinados interesses políticos internos.

No final da sua vida, Alberdi tentou escrever um texto de economia sintetizando seu pensamento e frustração em um tom de denúncia: a América Latina estava em um estado permanente de crise econômica, política e social. Essa percepção pode parecer equivocada quando se considera o processo de crescimento econômico que a Argentina iria experimentar a partir do final do século XIX. Mas, talvez, Alberdi estivesse denunciando problemas estruturais que se manifestariam nas inúmeras crises econômicas e políticas que a Região iria experimentar ao longo da sua história.

O artigo está dividido em três seções. A primeira trata das características e evolução do pensamento de Alberdi ao longo da década 1950 do século XIX. A segunda destina-se ao texto Bases. Na terceira, será analisado o livro Estudios. Nas conclusões, tentaremos sintetizar a importância do pensamento de Alberdi para a compreensão da formação de uma sociedade capitalista na América do Sul.

\section{Alberdi e a construção de uma nação}

Juan Bautista Alberdi nasceu na Província de Tucumã, na Argentina em 1810 e faleceu em Paris, em 1884. Foi um dos principais intelectuais argentinos e sul-americanos do século XIX. Também teve grande atuação política ao denunciar as ações antidemocráticas do ditador Juan Manuel de Rosas e apoiar o Caudilho Justo José Urquiza como novo presidente da Confederação Argentina, logo após a queda do ditador, em $1852^{(4)}$. Urquiza teve-o como assessor e logo o nomeou para cargo diplomático, incumbindo-lhe a missão de obter na Europa o reconhecimento da Confederação Argentina e evitar que esse reconhecimento fosse destinado à rebelde cidade de Buenos Aires, que não reconhecia o caudilho de Entre Rios como presidente. Buenos Aires separa-se então das treze províncias e isso leva a Região a experimentar a situação insólita: o que era para ser uma Nação se dividiu em duas sendo uma delas uma cidade portuária. Esses acontecimentos eram, para Alberdi, uma divisão política equivocada e injusta.

Durante sua vida, Alberdi publicou inúmeros livros e textos sobre Direito, Política, Filosofia e Economia. Dentre as suas obras mais importantes e conhecidas, encontra-se Bases y Puntos de Partida para la Organización Política de la República Argentina, de 1852.

(4) Juan Manuel de Rosas ocupou o poder entre os anos de 1829 e 1832 e 1835 a 1852. Membro do Partido Federal, em oposição ao Partido Unitário, foi um caudilho representante das classes produtoras de gado com origem no comércio de Buenos Aires. Em 1852, Rosas é derrubado pelas forças do General Justo José Urquiza, um próspero caudilho produtor de gado na Província litorânea de Entre Rios e simpático ao federalismo. 
Nessa obra, Alberdi expressa o seu pensamento econômico e jurídico e as suas ideias para a "construção" da Argentina. Um interessante aspecto da obra foi destacado pelo historiador Leon Pomer e encontra-se no prefácio da edição de Bases em português, publicada pela Editora da Unicamp. Para Pomer, Bases foi "o compêndio mais perfeito de um ideário liberal escrito na América, ex-colônia espanhola, durante o século XIX" (POMER, 1994, p. 13). O fato é que Bases foi a principal referência para a elaboração do texto da Constituição da Argentina de 1853 e teve significativa influência na elaboração do Código Civil do país ${ }^{(5)}$.

Alberdi produziu outras obras como o Fragmento preliminar al estudio del derecho, publicando originalmente em 1837, as Cartas sobre la prensa y la política militante de la República Argentina, também conhecida como Cartas Quillotanas e o Sistema Económico y Rentístico de la Confederación Argentina, ambas publicadas originalmente em 1853, além de Grandes y Pequenos Hombres del Plata, obra publicada em 1865. Nos três últimos textos, expressou suas divergências políticas com aqueles que defendiam a soberania de Buenos Aires. Revelava também sua simpatia pelo Partido Federal. No texto Fragmento Preliminar, havia considerado a possibilidade de Rosas ser um autêntico representante do povo argentino.

Entretanto, Alberdi pensava também em outros aspectos dessa possível democracia. Naquele momento, havia, por parte do pensador, esperanças na estabilidade institucional que poderia ser possível no "Governo Restaurador" de Rosas. Essas esperanças, porém, desapareceram. Determinadas atitudes do caudilho passavam a desagradar Alberdi, que adotou um tom crítico em relação ao ditador. Essa postura levou-o ao exílio. E os acontecimentos que se seguiram após a queda de Rosas tornariam esse exílio voluntário até 1878, quando voltaria ao país unificado para assumir um cargo de deputado em sua cidade natal. Porém, não encontrando as instituições que tanto defendeu, retornou à Europa em 1881 para morrer em Paris três anos mais tarde.

No exílio, Alberdi não diminuiu as esperanças e manteve uma intensa produção de textos políticos e econômicos. Utópico ou não, pensava em uma nação integrada e para isso defendeu uma melhor distribuição do poder entre Buenos Aires e as províncias. Uma vez estabelecida essa distribuição, preocupou-se com a estabilidade institucional, que somente seria possível com a paz na região. Considerava que o fim dos conflitos entre as províncias seria alcançado se houvesse uma perspectiva de crescimento, de integração e, de certa forma, de inclusão. Porém, essas perspectivas não se concretizaram. Alberdi percebeu os equívocos cometidos pelos políticos de Buenos Aires após a queda de Rosas. O otimismo presente em sua obra Bases passaria então a ser substituído então por uma análise pessimista sobre o processo de formação política e econômica que estaria acontecendo na Argentina. Esse pessimismo é encontrado em seu livro Estudios Económicos, publicado dois anos após sua morte.

Estudios Económicos, que inicia o primeiro dos 16 volumes das suas obras póstumas, apresenta uma análise densa de uma situação histórica complexa, anárquica e contraditória. Nesse livro, Alberdi tentou sintetizar sua interpretação sobre a evolução histórica da Região e ao mesmo tempo buscou uma interpretação para uma crise que ele imaginava existir na América do Sul no século XIX. Apesar de ser um livro inacabado e incompleto em algumas

(5) Com algumas mudanças, a Constituição de 1853 vigorou até 1949, quando foi substituída por Perón (SHUMWAY, 2008, p. 177). 
partes, foi considerado, por autores de sua época, como José Ingenieros, um dos principais textos sobre a formação econômica e política da Argentina. A seguir, analisaremos as duas obras, tentando situá-las em seu contexto histórico.

\section{As bases Para a CONSTRUÇão de uma naÇão liberal}

Em 1852, Rosas foi derrubado pelas forças do General Justo José Urquiza, um próspero caudilho produtor de gado da Província litorânea de Entre Rios. Surgia então uma nova perspectiva à nação Argentina, à medida que Urquiza intencionava estabelecer outra Constituição, o que poderia significar um novo equilíbrio entre as forças políticas do país. Nesse mesmo ano, Alberdi publicava Bases y Puntos de Partida para la Organización Política de la República Argentina.

Bases foi um texto "militante", pois foi escrito em um momento de intensa atuação política do autor como oposição ao Governo de Rosas. O texto apareceu pela primeira vez em maio de 1852 na cidade de Valparaíso, no Chile e logo teve grande e positiva repercussão na imprensa chilena e argentina (MAYER, 1963, p. 412). Sua construção teve clara influência da literatura liberal da época, particularmente pelo contato que o autor teve com as obras de Adam Smith e Jean-Baptiste Say (MAYER, 1963, p 95)(6). Bases é texto jurídico, pois contém as diretrizes para um novo modelo institucional a ser implantado pelo governo a suceder Rosas. É um texto sobre política, pois discute questões referentes às disputas entre federais e unitários. É também um texto sobre economia, pois trata dos caminhos que o país deve trilhar para conseguir o progresso material. É, acima de tudo, um texto de ideologia liberal, visto que traça algumas diretrizes para que o país possa prosperar no capitalismo. Mas não pode ser considerado como um texto que simplesmente importava essa ideologia liberal dos economistas clássicos de sua época. Pelo contrário, Alberdi olhava para os interesses e para as características particulares da Região.

Alberdi inicia o texto Bases analisando as constituições experimentadas pela Argentina (1819 e 1826) e por algumas das recém-independentes nações latino-americanas ${ }^{(7)}$ :

Ninguna de las constituciones de Sud-América merece ser tomada por modelo de imitación, por los motivos que paso a ocuparme. [...] Todas las constituciones dadas en Sud-América durante la guerra de la independencia, fueron expresión completa de la necesidad dominante de ese tiempo. Esa necesidad consistía en acabar con el poder político que la Europa había ejercido en este continente, empezando por la conquista y siguiendo por el coloniaje; y como medio de garantir su completa extinción, se iba hasta arrebatarle cualquier clase de ascendiente en estos países. La independencia y la libertad exterior eran los vitales intereses que preocupaban a los legisladores de ese tiempo. Tenían razón; comprendían su época y sabían servirla. [...] En ese período,

(6) Esses autores, entretanto, não foram os únicos que influenciaram Alberdi, a sua formação intelectual teve impacto de autores iluministas como Condillac, Locke, Helvecio, Cabanis, Bentham, Lerminier, Villemain, Victor Hugo, Lamartine e Byron, dentre outros. Sobre essas influências, ver TERAN (2004, p. 12).

(7) A edição utilizada neste artigo é a de 1856. É considerada como edição oficial e definitiva. A primeira apareceu em 1852 em Valparaíso. A segunda surgiu meses depois na mesma cidade. Nesta e em outras citações, manteremos a versão original, que incluem estilos e grafias da época. 
en que la democracia y la independencia eran todo el propósito constitucional; la riqueza, el progreso material, el comercio, la población, la industria, en fin, todos los intereses económicos, eran cosas accesorias, beneficios secundarios, intereses de segundo orden, mal conocidos y mal estudiados, y peor atendidos por supuesto.(ALBERDI, 1943, p. 9-11.)

Para Alberdi, o novo sentido da emancipação seria o desenvolvimento econômico. Para tanto, considerava que a América Latina deveria elaborar leis de forma a estimular o comércio, a imigração, os investimentos e a implantação de regras ou instituições estáveis de forma que "algo dinâmico acontecesse" e que a sociedade pudesse desfrutar do progresso material decorrente. Pensou então em algumas pré-condições para esse progresso:

¿Por qué dudar, por fin, de la posibilidad de una constitución argentina, en que se consignen los principios de la revolución americana de 1810? ¿Son en qué consisten, qué son esos principios representados por la revolución de mayo? Son el sentido común, la razón ordinaria aplicados a la política. ¿La igualdad de los hombres, el derecho de propiedad, la libertad de disponer de su persona y de sus actos, la participación del pueblo en la formación y dirección del gobierno del país, qué otra cosa son sino reglas simplísimas de sentido común, única base racional de todo gobierno de hombres? (ALBERDI, 1943, p. 222.)

Nessa passagem, notamos uma importante questão e que ainda é considerada nas discussões sobre desenvolvimento nos dias atuais: o conceito de direito de propriedade. Alberdi era um jurista e procurava relacionar, com base na sua realidade, o conceito de direito de propriedade com o progresso material. Alberdi parece ter buscado esse conceito em Jean-Baptiste Say, como sugere a citação a seguir:

O filósofo especulativo pode ocupar-se em procurar os verdadeiros fundamentos do direito de propriedade; o jurisconsulto pode estabelecer as regras que presidem à transmissão das coisas possuídas; a ciência política pode mostrar quais são as garantias mais seguras desse direito; quanto à Economia Política, ela considera a propriedade apenas como o mais poderoso encorajamento à multiplicação das riquezas. Ela pouco ocupar-se-á com o que a fundamenta e garante, desde que ela seja assegurada. [...]. Só se pode dizer que a propriedade existe quando ela existe não somente de direito, mas de fato. É só então que a indústria obtém sua recompensa natural e que tira o maior partido possível de seus instrumentos: os capitais e as terras. (SAY, 1983, p. 133.)

De uma perspectiva mais geral, Alberdi parecia acreditar na estabilidade institucional como uma condição necessária para o desenvolvimento do seu país. Podemos afirmar que Alberdi lia, nos economistas clássicos, as doutrinas para a construção de uma economia de mercado. Esse é um ponto fundamental para a compreensão do pensamento do autor. A questão externa era apenas uma das muitas a serem consideradas. Inicialmente, era necessário um Governo e uma Constituição:

Las garantías individuales proclamadas con tanta gloria, conquistadas con tanta sangre, se convertirán en palabras vanas, en mentiras relumbrosas, si no se hacen efectivas por medio de las garantías públicas. - La primera de éstas es el gobierno, el poder ejecutivo revestido de la fuerza capaz de hacer efectivos el orden constitucional y la paz, sin los cuales son imposible la libertad, las instituciones, la riqueza, el progreso. 
La paz es la necesidad que domina todas las necesidades públicas de la America del Sud. - Ella no necesitaría sino de la paz para hacer grandes progresos.

Pero no lo olvidéis: la paz sólo vienes por el camino de la ley. La constitución es el medio más poderoso de pacificación y de orden. (ALBERDI, 1943, p. 184-185.)

Interessante notar a interpretação que Alberdi (1943) faz de sua época ao constatar o fato de que as constituições latino-americanas teriam sido concebidas como imitações das constituições da França e dos Estados Unidos:

En su redacción nuestras constituciones imitaban las constituciones de la República francesa y de la República de Norte-America. [...] Sabido es que la revolución francesa, que sirvió a todas las libertades, desconoció y persiguió la libertad de comercio. [...] Los Estados Unidos no eran de mejor ejemplo para nosotros en política exterior y en materias económicas, aunque este parezca extraño. [...] Desmembración de un Estado marítimo y fabril, los Estados Unidos tenían la aptitud y los medios de ser una y otra cosa, y les convenía la adopción de una política destinada a proteger su industria y su marina contra la concurrencia exterior, por medio de exclusiones y tarifas. Pero nosotros no tenemos fábricas, ni marina, en cuyo obsequio debamos restringir con prohibiciones y reglamentos la industria y la marina extranjera, que nos buscan por el vehículo del comercio. (ALBERDI, 1943, p. 12.)

Três considerações merecem destaque na análise dessa citação: (I) Alberdi estava atento aos problemas decorrentes da simples imitação de modelos externos, isto é, procurava em Bases uma perspectiva latino-americana, ainda que sob uma leitura liberal de influência clássica europeia $^{(s)}$; (II) Alberdi já denunciava, em 1852, o protecionismo comercial para estimular a indústria nos Estados Unidos e na Europa, ou seja, percebia que muitos países adotavam políticas contrárias ao princípio liberal presente no conceito das vantagens comparativas; (III) para Alberdi, ainda não estava claro qual seria o papel da Argentina no sistema de divisão internacional do trabalho a ser implantado a partir da segunda metade do século XIX.

O autor preocupava-se em como organizar uma nação com condições institucionais mínimas para que o progresso econômico pudesse ocorrer. Naquele momento, entretanto, Alberdi percebeu que a pecuária, tal como desenvolvida pelo Governo de Rosas, não poderia ser a atividade dinâmica que conduziria a Argentina ao desenvolvimento econômico e à integração, como já havia percebido Sarmiento, seu aliado intelectual por muitos anos, ao afirmar que:

[...] o gado é a indústria que ocupa a terra e exclui a população. [...] As vacas dirigem a política argentina! Que são Rosas, Quiroga e Urquiza? Apascentadores de Vacas, nada mais. Todos esses títulos de governador, general, restaurador, diretor são consequência da maneira estúpida, pobre, prejudicial de criar vacas, inutilizando o terreno, impedindo o povoamento e a indústria. (SARMIENTO, 1983, p. 38.)

Também nessa "fase inicial", era necessário povoar. Conforme as próprias estimativas de Alberdi, a Federação Argentina, em meados do século XIX, deveria ter cerca de 800

(8) Neste aspecto, nossa análise diverge da realizada por SHUMWAY (2008), que considera Bases um texto que afasta Alberdi de uma visão latino-americana. 
mil habitantes. Essa deveria ser uma das estratégias do Estado: "governar é povoar" seria a frase contida no título do capítulo 31 de Bases. Seria, então, papel do Estado dar garantias aos imigrantes, criar uma Constituição que pudesse garantir o direito de propriedade àqueles que desejassem se estabelecer em solo argentino. Permitir a diversidade religiosa já seria um grande passo. Mas Alberdi vislumbrava algo mais do que o simples povoamento. Se o povoamento do "deserto" interior era importante, também era necessário superar o seu isolamento e, para tanto, seriam necessários investimentos em infraestrutura de transporte e de comunicação.

Mas de onde viriam os recursos para tantos investimentos? Alberdi apresenta uma possibilidade que o revela muito mais preocupado com uma concepção mais geral de construção de uma nação capitalista do que o simples povoar de um vazio territorial. Reconhecia, entretanto, a ausência de capitais financeiros domésticos e percebeu as oportunidades de captação de poupança externa:

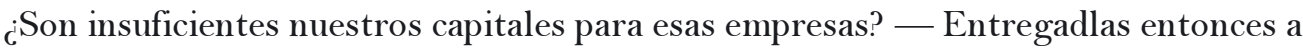
capitales extranjeros. Dejad que los tesoros de fuera como los hombres se domicilien en nuestro suelo. Rodead de inmunidad y de privilegios el tesoro extranjero, para que se naturalice entre nosotros. Esta América necesita de capitales tanto como de población. El inmigrante sin dinero es un soldado sin armas. Haced que inmigren los pesos en estos países de riqueza futura y pobreza actual. Pero el peso es un inmigrado que exige muchas concesiones y privilegios. Dádselos, porque el capital es el brazo izquierdo del progreso de estos países. Es el secreto de que se valieron los Estados Unidos y la Holanda para dar impulso mágico a su industria y comercio. (ALBERDI, 1943, p. 89.)

Alberdi foi criticado por alguns nacionalistas por essa postura ${ }^{(9)}$. É interessante notar que o discurso de Alberdi se volta para a união das províncias argentinas, situação que até então não havia se verificado na região. Essa união política, entretanto, implicava uma maior divisão de poder entre federais e unitários. No capítulo 17 de sua obra, Alberdi apresenta inúmeros argumentos que defendem as posições dos dois partidos. Vislumbrava um modelo conciliatório, tendo como referência os Estados Unidos. Imaginava um Estado Federativo composto pelas províncias independentes, porém subordinadas a um Governo Central. No capítulo 23, sugere algumas das atribuições para esse Governo: a política externa, a defesa, os investimentos em infraestrutura, a legislação sobre comércio, a navegação e dois importantes conjuntos de questões econômicas: o poder de emitir créditos internos e externos e o poder de arrecadar e distribuir as receitas tributárias. A primeira das faculdades faz sentido com base em um poder central. Logo, não é difícil justificar a sua defesa. O problema estaria no segundo conjunto de atribuições. A quase totalidade das receitas da Argentina era gerada no porto de Buenos Aires. Esse seria o grande problema que não foi resolvido após a vitória em Monte Caseros e que se tornaria uma das grandes desilusões de Alberdi em relação aos rumos tomados pela Argentina ${ }^{(10)}$.

(9) Um exemplo mais notável dessa crítica pode ser encontrado em IRAZUSTA (1963).

(10) Monte Caseros é o local onde o ditador Juan Manuel de Rosas foi derrubado pelas forças do General Urquiza. 
Após a construção institucional, qual seria a estrutura produtiva que deveria ser estabelecida no país? Conforme sugerido anteriormente, Alberdi não estaria pensando no modelo de divisão internacional do trabalho que poderia ser prejudicial à América Latina na interpretação de muitos economistas latino-americanos contemporâneos ${ }^{(11)}$. Poderia ser a indústria manufatureira, conforme ele sugere no capítulo 13:

La industria es el único medio de encaminar la juventud al orden. Cuando la Inglaterra ha visto arder la Europa en la guerra civil, no ha entregado su juventud al misticismo para salvarse; ha levantado un templo a la industria y le ha rendido un culto, que ha obligado a los demagogos a avergonzase de su locura. La industria es el calmante por excelencia. Ella conduce por el bienestar y por la riqueza al orden por el orden a la libertad: ejemplos de ello la Inglaterra y los Estados Unidos. La instrucción en América debe encaminar sus propósitos a la industria. (ALBERDI, 1943, p. 62.) (12) $^{(12)}$

Alberdi pensava na industrialização como uma possibilidade. Pensava antes na qualificação da mão de obra. Não o simples "educar o povo", mas orientar a educação para as ciências exatas e artes aplicadas à indústria. Alberdi reclamava do excesso do ensino do que denominou de ciências morais em detrimento das ciências exatas. Considerando que a indústria demandaria a instrução da engenharia e de atividades afins, fazia sentido pensar na qualificação da mão de obra como alternativa para a implantação de indústrias no futuro. Alberdi pensava, entretanto, em uma atividade econômica especial a ser estimulada de imediato: o comércio e a navegação no rio da Prata. Prestava atenção na posição estratégica das terras para as pastagens ou agricultura em relação à penetração do rio no interior da América do Sul. Essa seria uma vantagem evidente e, mais uma vez, a questão fiscal se colocava como fundamental:

De todas las industrias conocidas, el comercio marítimo y terrestre es la que forma la vocación especial de la República Argentina. Ella deriva esa vocación de la forma, producciones y extensión de su suelo, de sus portentosos ríos, que hacen de aquel país el órgano de los cambios de toda la América del Sur y de su situación respecto de la Europa. - Según esto, la libertad y el desarrollo del comercio interior y exterior, marítimo y terrestre, deben figurar entre los fines de primer rango de la constitución argentina [...]. La libertad del comercio interior sólo será un nombre, mientras haya catorce aduanas interiores, que son catorce desmentidos dados a la libertad. La aduana debe ser una y nacional, en cuanto al producto de su renta; e en cuanto a su régimen reglamentario, la aduana colonial o fiscal, la aduana inquisitorial, iliberal y mezquina de otro tiempo, la aduana intolerante, del monopolio y de las exclusiones, no debe ser la aduana de un régimen de libertad y de engrandecimiento nacional. (ALBERDI, 1943, p. 122-123.)

(11) Aqui, podemos destacar o pensamento cepalino, que considerou a especialização produtiva decorrente da adoção do livre comércio como uma situação prejudicial para a América Latina. Prebisch, por exemplo, denominou tal modelo de Centro-Periferia.

(12) Aqui, podemos ter uma interpretação acerca da palavra "indústria" que pode comprometer a análise do texto. Indústria, em textos de autores do século XIX, particularmente na primeira metade do século, poderia significar qualquer atividade produtiva, como comércio, agricultura etc. A indústria de transformação era designada por "manufatura" ou algum termo semelhante. No contexto da citação, Alberdi parecia se referir à atividade manufatureira. Essa interpretação torna-se clara quando se toma a leitura do capítulo XIII como um todo. Mas, muitas vezes, Alberdi se refere à indústria como uma atividade geral, como na próxima citação. 
Alberdi estaria ainda por perceber que a questão fiscal seria um dos grandes entraves à unificação do país. Sob a influência de Bases, em 1853 é implantada a Constituição da Federação Argentina. Por prever a federalização das receitas do porto, aquela que seria a Capital da Nação, declara-se como país independente. A divisão política que era observada na ditadura de Rosas é ampliada. Alberdi, em uma nova edição de Bases, de 1856, buscou, na história e nas instituições, as causas dessa situação:

El error de Rivadavia no consistía en haber dado a su provincia instituciones inadecuadas, como se dice vulgarmente, sino en que empezó por atribuir a la provincia de Buenos Aires los poderes y las rentas que eran de toda la Nación. Cuando más tarde quiso retira esos poderes y rentas para entregarlos a su dueño, que es el pueblo argentino, ya no pudo; y la obra de sus errores fue más poderosa que la buena voluntad del autor. En nombre de sus propias instituciones de desquicio, Rivadavia fue rechazado por Buenos Aires, desde que pensó en dar instituciones de orden nacional. (ALBERDI 1943. p. 278.)

Bernardino Rivadavia foi uma das personalidades políticas mais relevantes da história da Argentina. Esteve no poder entre 1821 e 1827, primeiro como Ministro das Relações Exteriores do Governo Federal do General Martin Rodriguez e depois como Presidente ${ }^{(13)}$. Rivadavia liderou, durante os anos de 1820, um governo relativamente próspero em Buenos Aires. Essa prosperidade já era decorrente do grande dinamismo adquirido pelo porto, resultado do comércio de couro e carnes salgadas com a Europa, Caribe e Brasil. Esse dinamismo, apesar de não ter contribuído para qualquer mudança no quadro estrutural social no interior, que era de estagnação e de não integração, foi acompanhado pelo surgimento de uma classe alta emergente com o fascínio pelos costumes da aristocracia europeia (SHUMWAY, 2008, p. 121). Rivadavia soube aproveitar esse momento e conduzir a cidade de Buenos Aires para uma feliz experiência, pelo menos sob o ponto de vista das elites portenhas que, cada vez mais, consolidavam o seu poder econômico e diversificavam suas atividades, migrando para a pecuária na região pampeana graças às generosas transferências de terras proporcionadas pelo então poder público (ROCK, 1994).

Em estudo publicado originalmente no ano seguinte ao de Bases, denominado Derecho Publico Provincial Argentino, Alberdi haveria de considerar de forma mais energética a hipótese de que durante o governo de Rivadavia, as leis teriam dado poderes suficientes ao Governo de Rosas para legislar em benefício da arbitrariedade e do despotismo (ALBERDI, 1998). Não tanto por culpa de Rivadavia, que, segundo Alberdi, tentou modernizar a nação; queria chamar a atenção para a importância e para os cuidados com a construção da estrutura institucional de um país.

Alberdi já enxergava, na década de 1850, que as disputas políticas tinham uma motivação econômica e uma origem histórica. Em seu Fragmento Preliminar, Alberdi não percebeu de imediato tal questão e talvez aí resida a sua ingenuidade em seu apoio precipitado ao governo "restaurador" de Rosas. Porém, Rosas havia apenas consolidado o poder de uma

13) O uso do termo "presidente" aqui não é adequado, pois não podemos considerar a existência de uma República consolidada na região. Entretanto, na história argentina, Rivadavia é considerado como tendo sido presidente de uma nação em construção durante a década de 20 do século XIX. 
elite de comerciantes na cidade de Buenos Aires e que estaria migrando para a produção de gado na região do litoral. Após sua queda, essa elite procurou defender os seus interesses e entre esses estava a supremacia e autonomia da cidade portuária. Essa defesa acabou contribuindo para mais duas décadas de disputas sangrentas entre federais e unitários. Nesse período, Alberdi manteve o seu ofício de escrever sobre a Argentina, agora não mais tentando pensar em como construir uma nação, mas buscando entender as causas do fracasso no processo dessa construção em um tom de perplexidade e frustração. O seu liberalismo não era o liberalismo defendido por muitos intelectuais e políticos de Buenos Aires. Para entender tais sentimentos, devemos avançar no tempo e buscar a leitura de um Alberdi mais maduro, tentando escrever um livro sobre os problemas econômicos da América Latina após um período de conflitos, com a Guerra do Paraguai ${ }^{(14)}$.

\section{O eConomista em Estudios Económicos}

Após escrever Bases e durante o Governo de Urquiza, Alberdi passa a representar diplomaticamente a Confederação Argentina, constituída então pelas treze províncias menos a de Buenos Aires. Conforme destacado anteriormente, essa representação acabou se transformando em um exílio permanente até o final de sua vida, o que não o impediu de manifestar opiniões sobre determinados aspectos da formação Argentina. Em seus textos posteriores à publicação de Bases, passou a explicitar suas divergências políticas com aqueles que defendiam a soberania de Buenos Aires. Revelava também sua simpatia pelo Partido Federal. Mas esse apoio não se destinava ao federalismo de Rosas, pois o ditador era fruto de circunstâncias infelizes, representante dele mesmo e de interesses de uma oligarquia que passaria a dominar as forças econômicas e políticas do país. Todas essas percepções passam a ser encontradas no texto Estudios Económicos.

Em inúmeras obras publicadas ao longo de sua vida, é marcante a influência recebida por Alberdi dos economistas clássicos ${ }^{(15)}$. Em Estudios Económicos, o autor toma como uma das referências principais a obra clássica de Adam Smith: A Riqueza das Nações.

El comercio y las manufacturas no pueden florecer mucho tiempo en un estado que no goza de una administración de justicia bien reglada; en el cual no se siente la posesión de sus propiedades perfectamente garantidas; en el cual la fe de los contratos no es apoyada por la ley; y en el que o se ve a la autoridad pública prestar su fuerza de una manera constante y regular para compeler al pago de las deudas a todos aquellos que están en situación de pagarlas. En una palabra, el comercio y las manufacturas rara vez se verá florecer en un estado en que la justicia del gobierno no inspira un cierto grado de confianza. (SMITH apud ALBERDI, 1996, p. 222.)

Alberdi reafirmava sua preocupação com a estabilidade de regras, com o respeito aos contratos, com a estabilidade institucional e com o respeito ao direito de propriedade,

(14) Conforme destacado em nota anterior, essa evolução também é considerada por TERÁN (2004), porém, considerando todos os textos póstumos de Alberdi.

(15) Vale notar que, conforme indicado na nota 6, os economistas clássicos não foram os únicos considerados por Alberdi Mas a predominância deles é marcante em Estudios. 
condições mínimas para que o capitalismo pudesse prosperar na Região do Prata. Considerava que a região deveria elaborar leis de forma a estimular o comércio, a imigração e os investimentos em ferrovias de forma que o capitalismo pudesse prosperar e que a sociedade pudesse desfrutar do progresso material decorrente.

Se em Bases a preocupação com a estabilidade institucional já se colocava, pois havia, para ele, outros intelectuais de sua época, a percepção de que a Argentina mantinha os traços feudais herdados da colonização espanhola, em Estudios, essa preocupação é retomada em um novo contexto: Alberdi já tinha vivenciado a separação de Buenos Aires das demais províncias em 1853. Sua interpretação era a de que a Argentina teria cometido uma série de equívocos econômicos e políticos e perdido a oportunidade de ser uma verdadeira e próspera nação capitalista. Ou seja, após a queda do ditador, Alberdi teria visto suas expectativas frustradas. Sua concepção de uma nação liberal não apenas não teria sido concretizada como também a região teria se lançado em uma sangrenta guerra civil liderada por Buenos Aires, representada inicialmente pela figura de Bartolomé Mitre e depois por Domingo Faustino Sarmiento ${ }^{(16)}$. Todo esse caos institucional, na visão de Alberdi, teria comprometido o progresso econômico e social na região. É essa a hipótese que Alberdi tenta defender em sua obra Estudios.

Além das questões institucionais, Alberdi buscou outro conceito em Adam Smith (1976): o do trabalho improdutivo, que o autor da Escola Clássica desenvolve no livro segundo, capítulo terceiro da A Riqueza das Nações. Considerou não apenas esse conceito, mas relacionou-o com uma atividade que foi objeto de análise em boa parte de sua obra: o mau uso do crédito: "Las crisis consisten en ese empobrecimiento o destrucción de capitales y fortunas traídas por los empréstitos enormes, invertidos en asalariar trabajos improductivos." (ALBERDI, 1996, p. 83.)

Alberdi considerou a crise econômica como um fenômeno novo e deixa implícito que ela seria decorrente da formação do capitalismo nesta parte da América:

Las crisis económicas, en que esa pobreza consiste, son siempre nacidas del abuso de un noble esfuerzo, el de enriquecer y prosperar súbitamente. Ellas forman una pobre peculiar de los ricos, como existen enfermedades peculiares de los hombres robustos. Eran desconocidas antes de la época de los bancos y del crédito, como las explosiones y sus estragos lo eran antes del vapor aplicado a la locomoción. (ALBERDI, 1996, p. 37.)

Nota-se, nessa última passagem, que Alberdi sugere que as crises econômicas não teriam origem apenas no "lado real" do capitalismo, mas também no seu "lado financeiro". Alberdi considerava a crise econômica como uma manifestação particular do capitalismo que naquele momento parecia florescer na América do Sul: um capitalismo financeiro baseado no mau uso do crédito. Entretanto, mais do que a complexidade das operações de crédito, Alberdi se preocupou particularmente com o crédito nas mãos do Governo.

(16) Bartolomé Mitre ocupou o cargo de Presidente da Argentina entre 1862 e 1868 . Representante do Partido Unitário e dos interesses de Buenos Aires foi personalidade política importante a partir da década de 1860, e escritor e historiador: Teve a infelicidade ou o oportunismo de dar início à Guerra do Paraguai em 1865. Sarmiento ocupou a presidência entre 1868 e 1874 e encerrou o mesmo conflito, que foi impopular não apenas no meio da sociedade argentina, mas entre intelectuais da época. Sobre essa impopularidade, ver SHYNWAY (2008, p. 83). 
Finalmente, nessas considerações teóricas, Alberdi passa a considerar outra causa para a crise, talvez a mais grave de todas: as guerras, tão comuns na região durante o XIX:

El primero de los hechos en que las crisis tienen causas y origen es la guerra.

Toda guerra, por justa y gloriosa que sea en sus motivos, es causa de empobrecimiento, por los grandes gastos improductivos que ocasiona, por la destrucción de fortunas y de hombres, que son su efecto y condición natural.

La guerra puede ser fértil en gloria, fecunda en honores, pero esa gloria y esos honores cuestan siempre al país la disminución de su fortuna pública y privada, la disminución del trajo, la caída de los salarios, la emigración de los trabajadores y de los capitales, la paralización de todas las empresas de progreso material, la disminución de las entradas del tesoro, la desaparición de los metales preciosos, la contracción o disminución del crédito, la depresión de todos los valores, la pobreza general del país en una palabra, o ese estado de cosas más o menos permanente que se llama crisis, el menos gloriosos, como que es el descrédito, más humillante que la esclavitud. (ALBERDI, 1996, p. 55.)

Todas essas causas de uma crise, ou seja, a instabilidade institucional, a ausência do direito de propriedade, os desrespeitos aos contratos, a herança colonial, o mau uso do crédito, o trabalho improdutivo e as guerras se misturam na Região do Prata, tornando-a um mundo caótico totalmente desfavorável ao desenvolvimento de um capitalismo que Alberdi idealizou. O autor viu esse caos não como uma situação do acaso, mas como necessária aos interesses daqueles que desejavam fortalecer o poder da cidade e do porto de Buenos Aires sobre as demais regiões, cidades ou povoados do interior. Viu também que o caos demandava um combustível, que eram os financiamentos externos para os conflitos. Nesse ponto, passou a responsabilizar a Europa, particularmente, a Inglaterra, pelos empréstimos destinados aos conflitos na região, inclusive aqueles destinados à Guerra do Paraguai.

Alberdi, apesar de ter como referência teórica os economistas clássicos liberais, não foi um mero importador de teorias. Sua percepção de que algo estava errado nessa parte da "América" e que interesses políticos se colocavam nas crises que ele imaginava existir. Após essas referências, Alberdi busca na história as oportunidades e os erros cometidos na Região do Prata. No que seria o terceiro capítulo do seu livro, intitulado Causas históricas de origen colonial, Alberdi busca na história colonial as causas para um estado de pobreza que ele julgava estar presente em toda América Espanhola. Seu rancor pela colonização espanhola é revelado em passagens como esta, da qual extraímos um trecho:

La América antes española es pobre desde su origen y por causa de su origen, que debió a una nación pobre ella misma cuando la descubrió y conquistó, a causa de una guerra santa de ocho siglos en que olvidó o prendió a ignorar el trabajo, que e la sola fuente de la riqueza como su ausencia es la sola causa de la pobreza. [...] Mal poblada, porque lo fue por una nación despoblada ella misma por una guerra de ocho siglos, recibió en herencia orgánica la ignorancia y el desden al trabajo; el odio a la fe disidente; el amor a la adquisición del oro sin trabajo; el error de que tener menas era ser rico, con tal de tener esclavos para hacerlos trabajar; el error de que extender los dominios, es decir, el suelo de la corono, era extender su poder y grandeza; el odio a 
todo extranjero disidente en religión; su comercio y trato, mirado como crimen peligroso para la seguridad de la tierra; el aislamiento como principio de existencia social y garantía de seguridad contra la condición del extranjero […]. (ALBERDI, 1996, p. 87-88.)

Alberdi via a independência como uma oportunidade de ruptura desse modelo. Entretanto, sua leitura do processo de formação da economia argentina, por ocasião da concepção do texto Estudios, é pessimista. Naquele momento, o autor já tinha experimentado suas frustrações políticas ao interpretar o processo de formação dos Estados Nacionais da América do Sul, particularmente da Argentina.

Desde a separação de Buenos Aires das demais províncias em 1853, Alberdi passou a assumir um tom crítico em seus textos. A crítica, que cresce e que muitas vezes assume um tom de denúncia, tem um destino: as ações que o Partido Unitário e os governos de Bartolomé Mitre e de Domingo Faustino Sarmiento, passam a assumir após a queda de Rosas. Na verdade, as causas do que Alberdi chamava de crise eram específicas: estavam relacionados aos interesses de Buenos Aires, particularmente em relação ao destino das receitas da aduana do porto e à possibilidade dessa cidade em usar o crédito para se impor perante as demais províncias. Alberdi já havia denunciado os abusos de Mitre e Sarmiento em obras anteriores, mas em Estudios procurou avaliar esses dois governos a partir de um quadro já consolidado, tentando relacioná-los ao caos institucional ${ }^{(17)}$.

Alberdi procura dividir o processo de formação da história econômica da América do Sul, particularmente da Argentina, em dois grandes períodos e que depois o autor iria caracterizar como "ciclos", ou seja, momentos de progresso seguidos por períodos de decadência econômica e política (ver, por exemplo, Alberdi, 1996). O 1º período inicia-se com o fim da dominação colonial e se estende até o fim do governo de Juan Manuel de Rosas, cujo poder teria prevalecido entre 1829 e 1851 . O 2oㅡón perío iniciou-se com a queda do ditador e seria, segundo Alberdi, o momento da grande oportunidade para a prosperidade do capitalismo na região. Mas, por uma série de decisões equivocadas tomadas pelos homens do poder da cidade de Buenos Aires, tal oportunidade teria sido desperdiçada. Mais do que uma simples divisão de períodos, esses momentos, para Alberdi, eram como "ciclos".

O autor via o progresso econômico na região como um processo que, em um momento inicial, haveria uma perspectiva de prosperidade que logo seria frustrada pela falta de uma organização institucional mínima necessária ao progresso. O "combustível” para o início de cada ciclo era o crédito, concedido de duas formas: ou por endividamento interno ou principalmente pela utilização de recursos provenientes do exterior, ou seja, pelos empréstimos recebidos da Inglaterra. Esse primeiro ciclo de prosperidade não se sustenta e termina com uma situação anárquica sob o ponto de vista político, em grande parte fruto da herança colonial. Essa desorganização teria dificultado a construção de instituições favoráveis ao desenvolvimento econômico. As disputas pelo poder, as dificuldades em construir regras estáveis, as lutas territoriais, enfim, a conhecida "anarquia argentina" teria então resultado na ditadura do caudilho Juan Manuel de Rosas (também conhecido como o "Restaurador"), dentre outras ditaduras em outras regiões da América Latina.

(17) Um dos tex tos críticos mais conhecidos de Alberdi foi escrito em 1853 e é conhecido como Cartas Quillotanas. Nessas Cartas, faz duras críticas à Sarmiento e ao Partido Unitário (ALBERDI, 2004). 
Alberdi, no mesmo capítulo, não isenta a Europa pela crise. Além da própria colonização, ela teria alimentado o caos institucional com seus capitais financeiros ou empréstimos. Mais do que isso, teria beneficiado determinados grupos em detrimento de um poder mais democrático em uma região com tantas disputas políticas. A Europa, particularmente a Inglaterra, fornecia o combustível para a situação, que era a ausência de instituições. Para Alberdi, a concessão dos empréstimos externos seria um ato irresponsável em um momento em que a organização dos Estados Nacionais ainda não estava constituída.

A preocupação de Alberdi, entretanto, não estaria no primeiro ciclo, mas em um segundo ciclo, que começaria após a queda de Rosa em $1952^{(18)}$. Essa é uma observação relevante, apesar de um dos seus primeiros admiradores, o intelectual e pensador argentino do início do século XX, José Ingenieros, insistir na tese de que Alberdi, em Estudios, é o primeiro a perceber as consequências econômicas do governo de Rosas. Ingenieros vai além. Coloca Estudios junto com as obras de Sarmiento:

[…] Desenvolviendo ideas precedentes, y aplicando al estudio de los problemas americanos ciertas doctrinas económicas e históricas que dominaba, Alberdi llegó a dar una interpretación económica de la historia política argentina. Por este aspecto su obra completa a la de Sarmiento, que estudió otros factores, el medio y la raza. Los dos, juntos, contienen todos los elementos para una interpretación integral de nuestra evolución sociológica. (INGENIEROS, 1918, p. 355.)

Com esse argumento, José Ingenieros teria prestado atenção apenas em parte da análise histórica que Alberdi teria realizado. Teria observado apenas o primeiro período, ou seja, as consequências da herança colonial. Na verdade, Ingenieros e tantos outros intelectuais argentinos procuraram ignorar as duras críticas que Alberdi fez às duas grandes personalidades da política e da literatura argentina de sua época: Mitre e Sarmiento. Mais do que isso, Alberdi, ao explicar o segundo ciclo de prosperidade, relacionaria o egoísmo de Buenos Aires em não querer dividir as receitas aduaneiras com o interior com os conflitos da Região do Prata, particularmente com a Guerra do Paraguai. Sua leitura é de uma construção capitalista pela violência.

Alberdi percebe uma segunda oportunidade (ou um segundo ciclo) para a América Latina a partir da queda de Rosas e da mudança do sistema colonial mantido pelo ditador e outras que o autor cita em seu estudo. As causas de reversão desse segundo ciclo decorreriam mais uma vez dos conflitos políticos; porém, nesse novo ciclo, seriam explicadas pela recusa de Buenos Aires em compartilhar as suas receitas e seu poder político com as demais províncias. Pelo menos na leitura de Alberdi, esse teria sido um infeliz modo do capitalismo se estabelecer na Argentina.

Alberdi considerava não apenas as guerras civis, mas o principal conflito de sua época: a Guerra do Paraguai. Para ele, essa Guerra teria sido mais um dos maiores equívocos conduzido por Buenos Aires. O autor mais uma vez considera a irresponsabilidade do

(18) Aqui, há uma aparente confusão no texto. Muitas vezes, Alberdi mistura a análise sobre a economia argentina com uma análise sobre a América do Sul, como se quisesse generalizar sua abordagem. Essa seria, de fato, sua intenção. Porém, como se trata de uma obra póstuma, imaginamos que o autor não teve tempo de concluir o trabalho. Nesse sentido, na maior parte das análises, a Argentina é o seu foco principal. 
endividamento externo, que poderia ser utilizado para a construção de um capitalismo que ele havia idealizado em sua obra Base:

Así como hay obras públicas para empréstitos, hay también empresas guerreras, grandes obras de especulación política para grandes empréstitos: verbigracia, la triple alianza y la guerra del Paraguay, concebidas como para motivar los diez o veinte millones tomados a préstamos por el presidente Mitre y los treinta millones del presidente Sarmiento [...]. Arruinado el crédito de la confederación por sus empréstitos extravagantes y exorbitantes, cuyo producto ha sido empleado estérilmente en guerras que han desplobado parte de su suelo y riqueza, Sarmiento ha acabado de poner a la nación en manos de Buenos Aires, que es hoy el poseedor exclusivo de la rama principal del tesoro argentino, que es el crédito publico. (ALBERDI, 1996, p. 209.)

Em outra passagem, Alberdi parece insinuar uma contradição no uso dos empréstimos: a destruição de atividades produtivas, exatamente aquilo que a Argentina deveria buscar construir, como se estivesse reconhecendo os progressos realizados pelo Paraguai e pelas outras regiões atingidas pelos conflitos:

El empréstito inglés, de 1868, fue contraído para gastarse en destruir el Paraguay, cuya riqueza formaba parte de la riqueza del Plata, en buena economía, sin que la gloria de esas ruinas impida a la República Argentina se deudora de esos diez millones que está obligada a pagar con sus intereses. El empréstito de treinta millones levantado por la nación, para construcciones y obras de progreso, fue empleado, en gran parte, en las destrucciones gloriosas y liberales del Paraguay y de Entre Rios, por las guerras hechas contra Lópes y Urquiza, los iniciadores del vapor, del telégrafo, de la colonización, de la libre navegación fluvial, mientras los indios eran dejados en posesión del Sud. (ALBERDI, 1994, p. 187.)(19)

As consequências desses atos, para Alberdi, seriam um estado de pobreza e as suas várias manifestações nos âmbitos político, social e econômico:

La mayor y más genuina causa de la pobreza, en que nuestra crisis actual consiste, reside en su mal gobierno. [...] Hicieron tres guerras largas y sangrientas, que desalaron al Paraguay e Entre Rios, como para cegar en la fuente ulteriores campanas del género de la que, en 1852, libertó a la nación de su dictadura de veinte anos. Despoblaron a esos países, pos las tres guerras, de más de medio millón de sus habitantes y destruyeron millones de su riqueza pública y privada, que reemplazaron por otros tantos millones de dinero ajeno, en que endeudaron al país, hasta el grado de tener que investir por anos y anos, en el pago de intereses de esas dudas, la mitad de su renta pública ordinaria. (ALBERDI, 1996, p. 437-439.)(20)

Ainda que o texto Estudios Económicos não seja suficiente para concluirmos sobre todas as reais causas dos conflitos da Guerra do Paraguai e dos demais conflitos ocorridos

(19) O conflito de Entre Rios foi um dos vários conflitos que ocorreram na Argentina na segunda metade do século XIX. Rebelião liderada pelo General Ricardo López Jordán, na Província de Entre Rios, foi realizada em 1870 contra Urquiza e fortemente reprimido por Sarmiento, então Presidente da Argentina. O conflito contra Urquiza refere-se à separação de Buenos Aires das treze províncias, em 1853.

(20) Os três conflitos referem-se à Guerra do Paraguai, à rebelião liderada por López Jordán e à separação de Buenos Aires das treze províncias, que não foi pacífica. 
na região, ele sugere alguns pontos compartilhados por alguns historiadores, que reconhecem que esses conflitos devem ser entendidos como um processo inserido no contexto da consolidação do poder das elites portenhas sobre as demais províncias do interior da Argentina $^{(21)}$. A Guerra do Paraguai, além de destruir qualquer pretensão de união entre o forte poderio militar paraguaio com forças federais na Argentina, união essa que poderia ameaçar o poder dos de Buenos Aires, trouxe ganhos para produtores de gados e comerciantes da cidade portuária, mantendo assim os ganhos dos capitalistas portenhos (ROCK, 1994, p. 178).

A tragédia foi que a Guerra do Paraguai mudou a história econômica, política e social dos países que dela participaram. Também ajudou a consolidar no poder determinados grupos. Não era essa a história que Alberdi queria contar quando publicou sua obra Bases em 1852. Alberdi estaria, no final de sua vida, sentindo-se frustrado pela trajetória que a Argentina seguiu. Utópico ou não, imaginava que, após a queda de Rosas, a Argentina pudesse resolver suas questões políticas de forma mais democrática ou "civilizada", dando maior atenção às instituições e à inclusão do interior, dos caudilhos e gaúchos, nas decisões políticas e no destino das aduanas no porto. Interpretou os conflitos como o pior resultado da história da Argentina. O liberal não concordou com os rumos do capitalismo em seu país.

\section{Considerações FInAIS}

A leitura de Alberdi permite algumas considerações relevantes. Muitos conceitos e percepções que hoje são considerados no debate sobre o desenvolvimento econômico e político eram utilizados no século XIX. Alberdi utilizou o conceito de direito de propriedade e o argumento da estabilidade institucional para defender suas posições no debate sobre a política econômica na Argentina e, de certa forma, na América. O autor buscou na História um método de interpretação da realidade econômica e política. Alberdi também oferece um conjunto de questões que ainda podem ser exploradas e que podem ajudar na difícil tarefa de entender uma pergunta ainda não totalmente respondida ou compreendida: por que somos pobres?

Alberdi não viveu para ver seu país prosperar em um projeto liberal. Se olharmos o desempenho da economia argentina, perceberemos contradições no pensamento de Alberdi, particularmente em Estudios. Talvez a crise defendida por Alberdi não existisse na região. Essa possibilidade se reforça por alguns fatos históricos. A Argentina intensifica seu processo de integração à economia mundial a partir da década de 1880 . Inicia-se, então, a próspera produção de carnes, trigo e milho. Mais tarde, as técnicas de congelamento permitiriam a ampliação da pecuária bovina. Intensifica-se também a imigração europeia, que alcançaria seu auge na primeira década do século XX. A partir de então, a Argentina entraria em uma fase de crescimento que, até a grande depressão, teria poucos paralelos no mundo. Entretanto, após esse período de prosperidade, seria um país em permanente estado de crise econômica e política. Talvez aí esteja a relevância das ideias do autor.

(21) Essa tese é amplamente defendida por ROCK (1994), POMER (1980) e SHUMWAY (2008). 
Analisando as obras de Alberdi, podemos perceber várias críticas ao liberalismo que estava sendo construído na Argentina: um liberalismo baseado na concentração de renda e poder, concentração essa muitas vezes defendida pela repressão do Estado. Não houve um projeto nacional de desenvolvimento, pelo menos durante o período em que ocorreu o processo de concentração da renda, favorável aos proprietários da terra e àqueles vinculados às atividades de exportação. A cidade de Buenos Aires preferiu manter, naquele momento, sua hegemonia nas decisões acerca dos destinos das aduanas e essa decisão acabou por contribuir para o surgimento das guerras. Para Alberdi, a Guerra do Paraguai e os conflitos internos na Argentina representaram desperdícios de recursos materiais e financeiros, além de terem provocado grande instabilidade institucional e adiado e prejudicado o processo de imigração e integração do país. Sem dúvida, não podemos deixar de considerar que a Guerra do Paraguai mudou a história dos países que dela participaram. Alberdi percebeu a perversidade da situação em uma época em que muitos intelectuais defenderam o conflito, como Sarmiento e Mitre. Mais do que isso, percebeu uma possível relação de cumplicidade da Inglaterra com a situação, cumplicidade esta ainda hoje é debatida pelos historiadores ${ }^{(22)}$.

Infelizmente, Alberdi não pôde debater as contradições de seus argumentos. Não pôde observar os investimentos em ferrovias, que não foram utilizados para a integração do país, mas para a integração das fontes de bens primários ao porto. Também não conseguiu avaliar o processo de imigração: a Argentina atrairia grande contingente de pobres europeus que iriam se estabelecer na periferia das cidades. Não pôde acompanhar o desenvolvimento político de seu país, onde a liberdade econômica foi muitas vezes estabelecida com total ausência de democracia. Não viu a continuidade de uma situação: a violência seria uma sombra pronta para tornar-se real quando o "direito de propriedade" ameaçasse tornar-se mais justo. O gaucho e o caudilho seriam apenas personagens exóticos no processo de formação da estrutura econômica, política e social da Argentina.

\section{REFERÊNCIAS BibLIOGRÁFICAS}

ALBERDI, Juan Bautista. Grandes y pequeños hombres del Plata. Duenos Aires: Editorial Punto de Encuentro, 2007.

Cartas sobre la prensa y la política militante de la República Argentina (Cartas Quillotanas). Buenos Aires: Editorial Losada, 2004.

Derecho Público Provincial Argentino. Buenos Aires: Ciudad Argentina, 1998.

Bases y puntos de partida para la organización política de la República Argentina. Buenos Aires: Biblioteca Clásicos Argentinos, 1943.

Fragmento preliminar al estudio del Derecho. Buenos Aires: Libreria Hachette, 1937

Estudios económicos (Escritos póstumos de J. B. Alberdi - tomo I). Buenos Aires: Universidad Nacional de Quilmes, 1996.

Sistema económico y rentístico de la confederación argentina, según su Constitución de 1853. Buenos Aires: La Cultura Argentina, 1921.

(22) Ver, por exemplo, a discussão realizada por DORATIOTO (2007) e BETHELL (1995).

36 
BETHELL, Leslie (Org.). A Guerra do Paraguai: história e historiografia (introdução). In: Guerra do Paraguai - 130 anos depois. Rio de Janeiro: Relume Dunará, 1995.

DONGHI, Tulio Halperín. Proyecto y construcción de una Nación (1846-1880). Buenos Aires: Emecé Editores, 2007.

DORATIOTO, Francisco. Maldita guerra: uma história da Guerra do Paraguai. 2. ed. Cia. das Letras, 2007.

GHIRARDI, Olsen A. La filosofía en Alberdi. Cordoba: Ediciones da Academia Nacional de Derecho y Ciencias Sociales de Córdoba. 2000. v. IX.

GULDBERG, Horacio Cerutti. Historia de las ideas filosóficas latinoamericanas. In: GULDBERG, Horacio Cerutti; MAGALLÓNANAYA, Mario. Historia das las ideas latinoamericanas. ¿Disciplina fenecida? México: Casa Juan Pablos, Universidad de la Ciudad de México, 2003.

INGENIEROS, José. Sociología Argentina. Buenos Aires: Talleres Gráficos Argentinos L. J. Rosso y Cía., 1918.

IRAZUSTA, Julio. Influencia económica Britanica en el Rio de la Plata. Buenos Aires: Editorial Universitaria de Buenos Aires, 1963.

MAYER, Jorge M. Alberdi y su tiempo. Buenos Aires: Editorial Universitaria de Buenos Aires, 1963.

POMER, Leon. A Guerra do Paraguai: a grande tragédia rioplatense. São Paulo: Global, 1980.

- Apresentação à edição brasileira de bases: fundamentos da organização política da Argentina de Juan Bautista Alberdi. Campinas: Editora da Universidade Estadual de Campinas — Unicamp, 1994.

ROCK, David. Argentina: 1516-1987. Desde la colonización española hasta Raúl Afonsín. 4. ed. Buenos Aires: Alianza Editorial, 1994.

SARMIENTO, Domingos Faustino. Facundo. Buenos Aires: Grupo Editorial Planeta, 1983.

Textos selecionados. In: FERNANDES, Florestan (Coord.). Coleção Grandes Cientistas Sociais. São Paulo: Ática, 1983.

SAY, Jean-Baptiste. Tratado de economia política. São Paulo: Abril Cultural: Coleção Os Economistas, 1983.

SHUMWAY, Nicolas. A invenção da Argentina: a história de uma ideia. São Paulo: Edusp/Editora UNB, 2008.

SMITH, Adam. An inquiry into the nature and causes of the wealth of nations. v. II. Oxford: Clarendon Press, 1976.

TERÁN, Oscar. Las palabras ausentes: para leer los escritos póstumos de Alberdi. Buenos Aires: Fondo de Cultura Económica, 2004. 